\title{
Randomised double blind controlled trial of cyclosporin in multiple sclerosis
}

\author{
P RUDGE,* J C KOETSIER, † J MERTIN,* J O MISPELBLOM BEYER, \\ H K VAN WALBEEK, $\ddagger$ R CLIFFORD JONES, * J HARRISON,* K ROBINSON, $\S$ \\ B MELLEIN,\| T POOLE,\| J C J M STOKVIS, \| P TIMONEN\| \\ From the National Hospital for Nervous Diseases, London, UK, Department of Neurology, Free University \\ Hospital, Amsterdam, The Netherlands, $\dagger$ Onze Lieve Vrouwe Gasthuis, Amsterdam, The Netherlands, $\ddagger$ \\ Alphabridge Limited, London, UK,§ Sandoz Pharmaceuticals, London, Amsterdam, Basle\|
}

SUMMARY In a 2 year double blind controlled trial of cyclosporin against placebo in multiple sclerosis conducted at two centres there was a beneficial effect of the therapy upon the progression of the disease, relapse rate and relapse severity at one of the centres where the patients received a mean dose of $7 \cdot 2 \mathrm{mg} / \mathrm{kg} /$ day. This beneficial effect was not seen in the other centre where a lower dose (mean $5 \mathrm{mg} / \mathrm{kg} /$ day) was given. Reduction in clinical progression was accompanied by decreased IgG synthesis in the central nervous system. Side effects included hypertension, renal insufficiency and anaemia and were of such severity to preclude the use of cyclosporin in a high enough dose to alter the course of the disease.

There is a considerable body of evidence that immunological abnormalities are found in patients with multiple sclerosis, but it is unclear whether they are the cause of the central nervous system damage. ${ }^{1}$ Since similar abnormalities are found in experimental allergic encephalomyelitis, a disease of undoubted immunological origin, and because experimental allergic encephalomyelitis is modified by immunosuppressive therapy there have been numerous trials of immunosuppressive therapy in multiple sclerosis. ${ }^{2-626}$ While none of these trials has convincingly proven a beneficial effect of the treatment upon the course of the disease many do suggest that it is favourably modified.

Cyclosporin is a potent immunomodulating drug that is superior to conventional immunosuppressive therapy in maintaining viability of transplanted tissues. $^{78} \quad$ Furthermore, cyclosporin prevents experimental allergic encephalomyelitis if given prophylactically and can modify the disease when administered therapeutically, that is after the initial symptoms have developed in an animal immunised with myelin basic protein. ${ }^{9}$ The mode of action is unclear. In vitro it inhibits transcription of messenger RNA

Address for reprint requests: Dr P Rudge, The National Hospital for Nervous Diseases, Queen Square, London WC1N 3BG, UK.

Received 22 July 1988 and in revised form 25 November 1988. Accepted 28 November 1988 coding for lymphokines but its action in vivo is more complex. ${ }^{10-13}$ Although animals immunised with myelin basic protein in the presence of cyclosporin do not develop experimental allergic encephalomyelitis the disease does develop in a severe form after cyclosporin is stopped. ${ }^{14-16}$ Despite this uncertainty of action, and because of its effect therapeutically in experimental allergic encephalomyelitis, we decided to conduct a double blind controlled study of cyclosporin in multiple sclerosis.

\section{Methods}

\section{Patients}

The trial was conducted at two centres: London (1982-1986) and Amsterdam (1984-1986). The two centres independently randomised the patients into placebo and treated groups.

Criteria for admission to the trial were that the patients: (a) had clinically definite multiple sclerosis, ${ }^{17}(b)$ had evidence of active disease in that they either had an average of one relapse per year in the previous 2 years, or had evidence of progression of disability over the previous year, or both; $(c)$ were aged 15-50 years; $(d)$ were not pregnant and took active steps to avoid conception during the trial; $(e)$ had no other disease that would limit mobility such as ankylosing spondylitis and had no evidence of renal or hepatic disease; $(f)$ were ambulant but had significant disability. Two patients who fulfilled this criterion in the London group deteriorated immediately after selection, losing the ability to walk. They were included in the study (see table 1$) ;(g)$ did not have mental dysfunction precluding the ability to give informed consent. 
Table 1 Patient data on entry to trial (mean, standard deviation and range)

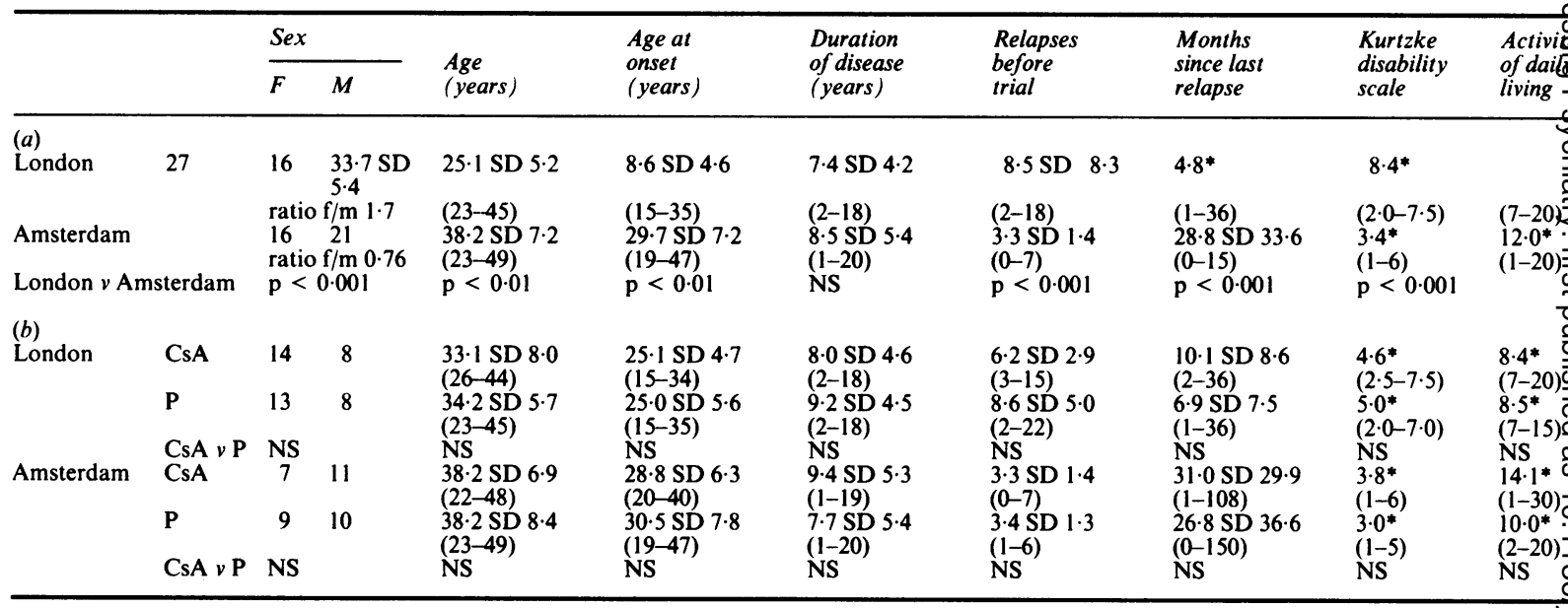

*Data not a normal distribution. CsA, cyclosporin; P, placebo.

\section{Neurological Assessment}

Entry into trial: Patients were admitted to hospital for assessment and randomised into treated or placebo groups. Initial evaluation included examination by the unblind observer. Blind assessment of neurological dysfunction was made by $(a)$ a neurologist who scored the patient's disability using the Kurtzke disability status scale and functional system scores, ${ }^{18}(b)$ an occupational therapist who determined a score of activities of daily living using the method of Sheikh (London), ${ }^{19}$ or incapacity scale (Amsterdam) ${ }^{20}$

Cerebrospinal fluid was examined for cells, IgG index, ${ }^{2 !}$. and presence of oligoclonal bands. The latency of the major positivity of the visual evoked potential from each eye was determined. ${ }^{22}$

Subsequent assessment: Neurological and general examination was done at weekly intervals by the unblind neurologist for 1 month after starting therapy during which the patient remained in hospital. These assessments were again carried out after discharge at 2 and 3 months from the beginning of the trial and thereafter at 3 monthly intervals.

Blind neurological assessment was carried out after discharge from hospital at 3 monthly intervals from the start of therapy for a total of 2 years. On each occasion the disability status scale and functional neurological scores were determined and an assessment made of the number of relapses that had occurred in the previous 3 months. A relapse was defined as a new neurological symptom, or significant worsening of an existing symptom, lasting more than 48 hours. The relapse severity was scored using the method of Millar. ${ }^{23}$ Every 6 months after the start of therapy an activities of daily living assessment was also made by the occupational therapist. After 2 years the patients were readmitted for their final blind assessment and further examination of cerebrospinal fluid and visual evoked potentials.

\section{Monitoring adverse events}

Full blood count, blood urea, serum electrolytes, creatinine, uric acid, total protein, albumin, bilirubin, alkaline phosphatase, alanine aminotransferase and routine urine examination were carried out at weekly intervals for the first month, monthly intervals for the next 2 months and 3 monthly intervals thereafter. The unblind assessor examined the patients for adverse events on each occasion and conducted a full general and neurological examination at these times.

\section{Therapy}

Patients received either cyclosporin oral solution (Sandimun, Sandoz, Basel) containing $100 \mathrm{mg} / \mathrm{ml}$ cyclosporin or placebo solution containing the vehicle alone. The initial dose of cyclosporin was $10 \mathrm{mg} / \mathrm{kg} /$ day for 2 months then $8 \mathrm{mg} / \mathrm{kg} /$ day for another 22 months in two equally divided doses, that is, a total of 2 years therapy. The dosage was controlled by the unblind assessor and could be modified if adverse effects occurred or if the serum creatinine exceeded $200 \mu \mathrm{mol} / 1$. The actual amounts received were different in the two centres (fig 1). Other drugs were allowed during the trial such as antispasticity agents or short courses of steroids for relapses, but these could only be prescribed by a doctor other than the unblind assessor.

\section{Statistical analysis}

(a) Intercentre (London $v$ Amsterdam) comparisons of patient data on entry to the trial: The following patient data; age, age at onset of the disease, duration of the disease, number of relapses at entry to the trial, and the number of months since the last relapse, from the two centres, were

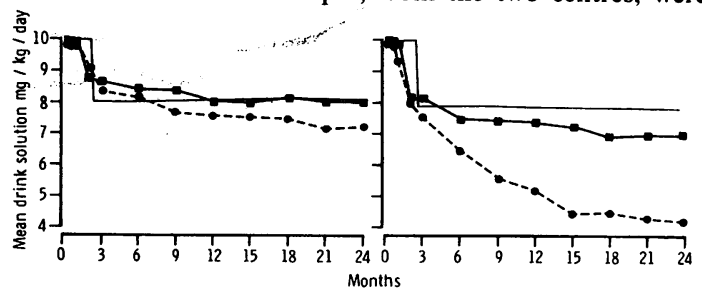

Fig 1 Amount of cyclosporin ( - - ) or placebo ( - ) oral solution taken over 2 year period in London (left) and Amsterdam (right). Intended dose shown by thin continuous line. 
compared using an unpaired $t$ test. Since the scores for Kurtzke disability and activities of daily living were not normally distributed at either centre a Mann Whitney U test was used to compare these patient data.

(b) Intergroup (placebo $v$ treated) comparisons of patient data on entry to the trial: The following patient data; age, age at onset of the disease, duration of the disease, number of relapses at entry to the trial, and the number of months since the last relapse, were compared using an unpaired $t$ test. The comparison was carried out separately for each centre. Since the scores for Kurtzke disability and activities of daily living were not normally distributed a Mann Whitney $U$ test was used to compare these patient data.

(c) Effect on disability (placebo $v$ treated groups) at 6 months, 12 months and 24 months.

(1) Kurtzke disability score: The effect on the Kurtzke disability score was analysed by using a two sided Fisher's exact test. Patients were categorised into one of two categories depending on whether the change from baseline (trial entry score) was at least one point or less. The time to deteriorate by one point on the Kurtzke disability scale was analysed by using life-table methods (Wilcoxon rank test).

(2) Activities of daily living and neurological functions: The effect on these measurements of disability was determined by using a Wilcoxon rank sum test.

(d) Effect on relapses (placebo $v$ treated groups): The number of relapses and the relapse severity were compared using Wilcoxon rank sum test. The time to the occurrence of the first relapse was analysed by life table methods (Wilcoxon rank test).

(e) Laboratory findings: IgG index and visual evoked response latencies were analysed using Wilcoxon rank sum test.

\section{Results}

\section{Baseline data}

Data on patients entering the trial: 82 patients entered the trial; 44 were in London and 38 in Amsterdam. At entry one patient in London was found to have evidence of acute hepatitis $A$ infection and another in Amsterdam had a misdiagnosis of acoustic neuroma. These two patients, both allocated placebo, were removed from the trial immediately without replacement. Thus 43 London patients ( 22 allocated cyclosporin) and 37 Amsterdam patients (18 allocated cyclosporin) entered the trial. Table 1 summarises these patient data.

It can be seen that the population in the London group differed from that in Amsterdam (table 1a). In brief, the London patients were younger at entry, had earlier onset of disease, although the duration of the disease was similar, were more disabled and had more relapses. Females exceeded males in London while the reverse obtained in Amsterdam. These differences suggest that the Amsterdam patients were selected primarily on the criterion of progression and the London patients on relapse rate. For these reasons the data from the two centres will first be presented and analysed separately followed by an assessment of the combined results. Comparison within each centre (table 1b) shows that there was no significant difference between the cyclosporin and placebo groups.

Withdrawal of patients: An intention to treat analysis was performed, that is, all patients, with the exception of two allocated cyclosporin in Amsterdam (see below), were included in the analysis whether or not they took the cyclosporin or placebo as dictated by the protocol. No patient was lost to follow up in either centre.

\section{London}

Of the 43 patients entering the trial eight stopped the treatment during the 2 year period; one became pregnant, two withdrew because of side effects (both allocated cyclosporin), and five wished to discontinue the medication (two allocated cyclosporin). One additional patient died at 13 months (placebo) and was scored at maximum disability thereafter, death being recorded as a relapse.

\section{Amsterdam}

Of 37 patients, two (allocated cyclosporin) withdrew from the trial before the first 3 month assessment and were not included in the intention to treat analysis. Of the remainder (35) all were included in the final analysis: two (one allocated cyclosporin) stopped taking the therapy because of side effects, and three (one allocated cyclosporin) wished to discontinue

\section{Effect on Clinical Course London}

Effect on disability: Since a change of 1 point on the Kurtzke disability scale is clinically important the disability data are presented for this interval. After 6 months' therapy significantly more patients $(p=0.03)$ had remained stable using the Kurtzke disability scale in the cyclosporin group. This effect was no longer apparent at 1 or 2 years after the start of the trial (table 2). Furthermore the time taken to decline at least 1 point on the Kurtzke disability status scale was longer in the cyclosporin group ( $p=0.07)$ (fig 2$)$.

This marginal benefit early in the course of cyclosporin therapy was also apparent in the change of the pyramidal, sensory and bladder and bowel functional neurological scores (but not the cerebellar, brainstem, vision, mental state or "other" scores) over the 2 years of the trial. The mean sum of the differences of all these scores (score at end minus that at the beginning) was $10.8 v 12.1$ for the cyclosporin and placebo groups respectively at 6 months $(\mathrm{p}=0.05)$ and $10.6 v 12.3$ at one year $(p=0.03)$. The effect was largely lost by 2 years. Activities of daily living assessment showed a slight benefit to the cyclosporin treated patients in that 
Table 2 Number of patients declining by 1 or more points on disability status scale

\begin{tabular}{|c|c|c|c|c|c|c|c|c|c|c|c|c|}
\hline \multirow{3}{*}{ Months } & \multicolumn{6}{|c|}{ London } & \multicolumn{6}{|c|}{ Amsterdam } \\
\hline & \multicolumn{2}{|l|}{6} & \multicolumn{2}{|l|}{12} & \multicolumn{2}{|l|}{24} & \multicolumn{2}{|l|}{6} & \multicolumn{2}{|l|}{12} & \multicolumn{2}{|l|}{24} \\
\hline & $C s A$ & $P$ & CsA & $P$ & $C s A$ & $P$ & $C s A$ & $P$ & $C s A$ & $P$ & $C s A$ & $P$ \\
\hline $\begin{array}{l}\text { Same or better } \\
\text { Worse } \\
\text { P }\end{array}$ & $\begin{array}{c}17 \\
5 \\
0 \cdot 03\end{array}$ & $\begin{array}{r}9 \\
12\end{array}$ & $\begin{array}{c}15 \\
7 \\
\text { NS }\end{array}$ & $\begin{array}{l}11 \\
10\end{array}$ & $\begin{array}{c}13 \\
9 \\
\text { NS }\end{array}$ & $\begin{array}{r}8 \\
13\end{array}$ & $\begin{array}{c}13 \\
3 \\
\text { NS }\end{array}$ & $\begin{array}{r}14 \\
5\end{array}$ & $\begin{array}{l}9 \\
7 \\
\text { NS }\end{array}$ & $\begin{array}{r}12 \\
7\end{array}$ & $\begin{array}{c}6 \\
10 \\
\text { NS }\end{array}$ & $\begin{array}{r}8 \\
11\end{array}$ \\
\hline
\end{tabular}

CsA, cyclosporin A. P, placebo.

the mean change over 2 years was $0.45 v 3.42$ for the cyclosporin and placebo groups respectively $(\mathrm{p}=$ $0.06)$.

Effect on relapses: Although there was no significant difference in the number of patients in the treated and placebo groups who had one or more relapses compared with those with no relapses through the 2 years of the trial the placebo patients accumulated twice as many relapses as the cyclosporin group $(p=0.07)$ the effect being more marked in the first year $(p=0.04)($ fig 3$)$. In addition the first relapse tended to occur earlier $(p=0.03)$ in the placebo group (fig 4) and the relapses were significantly more severe in the placebo group (table 3).

\section{Amsterdam}

There was no difference in the change of disability, rate of acquisition of disability or relapse rate between the placebo and treated groups of patients apart from a significantly greater $(p<0.05)$ accumulation of relapses in the second year of the trial in the placebo group.

\section{Pooled Data}

Because of the marked differences between the populations studied in Amsterdam and London, analysis of the pooled data is of dubious validity.

Significantly $(p<0.05)$ more patients remained stable on the Kurtzke disability assessment at 6 months but not thereafter in the cyclosporin than the placebo group. The time deterioration by one point on the disability status scale did not differ between the two groups. The deterioration in pyramidal, sensory, bladder and total functional scores was less in the treated group of patients but this was significant $(\mathrm{p}<$ 0.04 ) only in terms of bladder and bowel function at 6 months. Activities of daily living assessments could not be combined as different scoring systems were used in the two centres.

There were significantly $(\mathrm{p}<0.02)$ more relapses, which were more severe $(92.7 v 52.9, \mathrm{p}<0.014)$, in the placebo group of patients and they tended to occur earlier $(p=0 \cdot 10)$.

\section{Effect on laboratory data}

London

There was a significant reduction of the IgG index in the treated but not the placebo group of patients over 2 years $(-0.80 v-0.08, \mathrm{p}=0.05)$. Changes in the visual evoked potentials showed no differences between the cyclosporin and placebo groups.

\section{Amsterdam}

There was no significant difference between the placebo and treated patients on any laboratory measure.

\section{Adverse events: (table 4)}

Many of the adverse events listed are well known in patients receiving cyclosporin and it is noteworthy that infections were no commoner in the treated group. There are obvious difficulties in deciding whether some neurological adverse events, viz tremor and paraesthesiae, are due to the drug or the disease under investigation. It is clear that the Amsterdam investigators attributed these symptoms to cyclo-

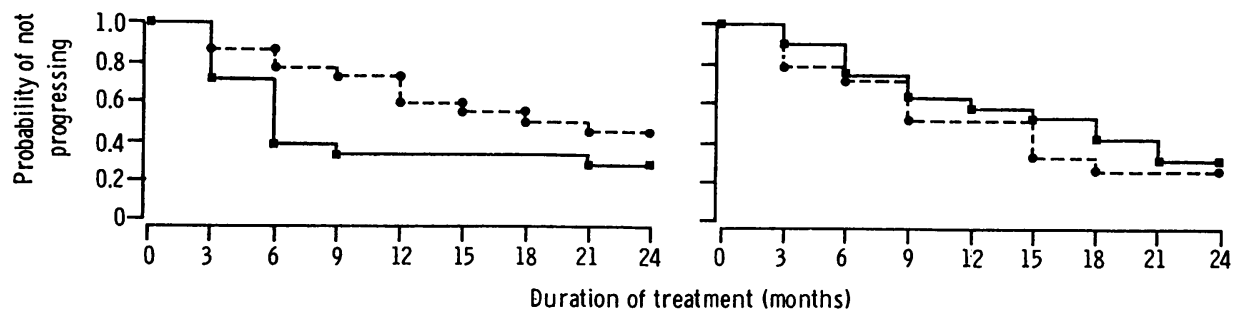

Fig 2 Probability of not progressing by at least 1 point on the Kurtzke disability status scale in cyclosporin (- ) and placebo (- groups in London (left) and Amsterdam (right). 


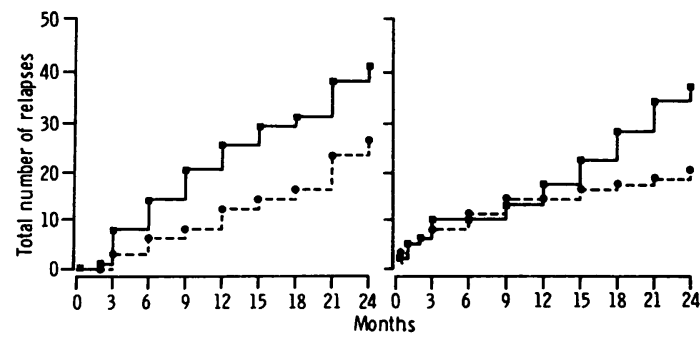

Fig 3 Accumulated number of relapses in cyclosporin ( - - ) and placebo ( $\square$ ) groups in London (left) and Amsterdam (right).

sporin while those in London considered them to be due to the disease. Furthermore it does appear that the investigators in Amsterdam had a lower threshold for reporting adverse events.

Serious adverse events were more frequent in London, where the patients received a higher dose of cyclosporin, than in Amsterdam. Fits occurred in three patients in London and dose responsive arthralgia was confined to that centre. A rise in blood pressure occurred in the vast majority of patients but was more severe in the London group who had a rather lower pre-treatment blood pressure. Thus after one year of therapy $53 \%$ and $47 \%$ respectively of the London patients had a systolic and diastolic blood pressure rise of greater than $15 \mathrm{~mm} \mathrm{Hg}$ compared with $30 \%$ and $36 \%$ for the Amsterdam patients. Further, the mean systolic and diastolic blood pressure rise at one year in the London group was approximately twice that of the rise seen in Amsterdam (21.5 $v$ 9.5 $\mathrm{mm} \mathrm{Hg}$ for systolic blood pressure and $18.2 v 9.6$ $\mathrm{mm} \mathrm{Hg}$ for diastolic blood pressure).

Renal function was adversely affected in nearly all the cyclosporin treated patients in that a rise in blood urea, serum creatinine and uric acid was seen in the majority. Thus serum creatinine and blood urea rose over the first 3 months and throughout the trial there was a highly significant difference between the placebo and treated patients. This deterioration in renal func-

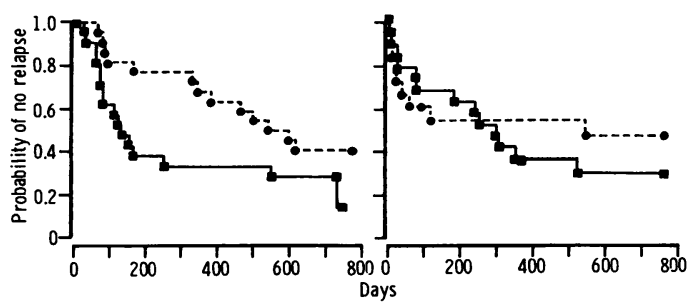

Fig 4 Survival distribution function of time to develop at least 1 relapse in cyclosporin ( $\left.-0_{-}\right)$and placebo

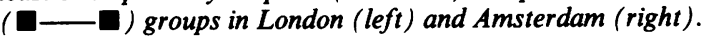

Table 3 Mean relapse score for patients with one or more relapse

\begin{tabular}{|c|c|c|c|c|c|}
\hline & \multicolumn{2}{|c|}{ Cyclosporin } & \multicolumn{2}{|l|}{ Placebo } & \multirow[b]{2}{*}{$p$} \\
\hline & $\begin{array}{l}\text { Number } \\
\text { of } \\
\text { patients }\end{array}$ & $\begin{array}{l}\text { Mean } \\
\text { relapse } \\
\text { score }\end{array}$ & $\begin{array}{l}\text { Number } \\
\text { of } \\
\text { patients }\end{array}$ & $\begin{array}{l}\text { Mean } \\
\text { relapse } \\
\text { score }\end{array}$ & \\
\hline London & 13 & \multirow{3}{*}{$\begin{array}{l}60 \cdot 5 \\
\text { SD } 47.9 \\
46 \cdot 7 \\
\text { SD } 61 \cdot 9 \\
54 \cdot 9 \\
\text { SD } 53 \cdot 1\end{array}$} & 15 & \multirow{3}{*}{$\begin{array}{l}117 \cdot 2 \\
\text { SD } 65 \cdot 9 \\
64 \cdot 7 \\
\text { SD } 63 \cdot 4 \\
92 \cdot 8 \\
\text { SD } 68.9\end{array}$} & 0.013 \\
\hline Amsterdam & 9 & & 13 & & $0 \cdot 15$ \\
\hline Pooled & 22 & & 28 & & 0.014 \\
\hline
\end{tabular}

Table 4 Adverse events (per cent)

\begin{tabular}{|c|c|c|c|c|}
\hline & \multicolumn{2}{|c|}{ Cyclosporin } & \multicolumn{2}{|l|}{ Placebo } \\
\hline & London & Amsterdam & London & Amsterdam \\
\hline $\begin{array}{l}\text { Hypertrichosis } \\
\text { Gingival }\end{array}$ & 47 & 94 & 5 & 6 \\
\hline $\begin{array}{l}\text { hyperplasia } \\
\text { Parasthesiae } \\
\text { Headache } \\
\text { Nausea } \\
\text { Seborrhoea } \\
\text { Menstrual }\end{array}$ & $\begin{array}{l}42 \\
11 \\
32 \\
16 \\
11\end{array}$ & $\begin{array}{l}64 \\
70 \\
52 \\
41 \\
29\end{array}$ & $\begin{array}{r}0 \\
0 \\
0 \\
11 \\
5\end{array}$ & $\begin{array}{r}12 \\
6 \\
0 \\
6 \\
6\end{array}$ \\
\hline \begin{tabular}{l}
\multicolumn{1}{c}{ disturbance } \\
Tremor \\
Arthralgia \\
Constipation \\
Depression \\
Skin
\end{tabular} & $\begin{array}{r}21 \\
5 \\
26 \\
16 \\
21\end{array}$ & $\begin{array}{r}0 \\
47 \\
6 \\
12 \\
0\end{array}$ & $\begin{array}{l}5 \\
0 \\
0 \\
0 \\
5\end{array}$ & $\begin{array}{r}6 \\
0 \\
0 \\
12 \\
6\end{array}$ \\
\hline $\begin{array}{l}\text { telangiectasia } \\
\text { Fits }\end{array}$ & $\begin{array}{l}21 \\
10\end{array}$ & $\begin{array}{l}0 \\
0\end{array}$ & $\begin{array}{l}0 \\
0\end{array}$ & $\begin{array}{l}0 \\
0\end{array}$ \\
\hline $\begin{array}{l}\text { Infections - urinar } \\
\text { - respira } \\
\text { Renal insufficiency } \\
\text { Hypertension } \\
\text { Anaemia }\end{array}$ & atory & see text & & \\
\hline
\end{tabular}

tion was greater in the London patients. Haemoglobin declined by about $10 \%$ over the first 6 months of the trial in the cyclosporin treated patients. The anaemia and hypertension resolved on stopping cyclosporin over a period of weeks but the renal impairment was more prolonged. Extensive renal investigation of these patients is being undertaken to see if there is any permanent glomerular or tubular deficit.

Blinding

There was no evidence that the patients guessed which preparation they received. In fact patients who did well thought they were taking the active preparation. No attempt was made to determine the blinding of the assessors.

\section{Discussion}

This trial shows that cyclosporin had a beneficial effect upon disease activity in multiple sclerosis as measured by rate of acquisition of disability and number and 
severity of relapses in one centre (London) but not the other (Amsterdam). The fact that these effects were largely confined to London could be due to the differences in patient groups studied, the drug regimen or a combination of these factors.

The patient population studied in Amsterdam was clearly different from that in London. The Amsterdam patients had a predominance of males, were significantly older, had fewer relapses prior to the trial and less disability than the London group. It was for this reason that the data from the two centres have been analysed separately. We doubt the statistical validity of the combined analysis.

More importantly the dosage of cyclosporin was different in the two centres. Because of this difference in dosage it is not possible to overcome the mismatch of the patients at the two centres by stratifying them, for example on disability, in order to analyse the combined data. However, it is tempting to argue that the higher dosage of cyclosporin in the London patients was the cause of the different outcome in the two centres. The patients in London received approximately the intended dose $(7.2 \mathrm{mg} / \mathrm{kg} /$ day $v 8.0$ $\mathrm{mg} / \mathrm{kg} /$ day) while those in Amsterdam received on average less than $5 \mathrm{mg} / \mathrm{kg} /$ day over the two years (fig 1). If this hypothesis that the higher dosage was beneficial is correct, there should be a correlation between the change in disability and the dose of drugs received by each patient within a centre. In London the range of doses was too small to enable such analysis to be done. In Amsterdam, where the dosage range was wider there was a tendency for the patients who received a lower dose to deteriorate more than those who received a higher dose but there were too few patients to allow a definitive conclusion.

During this study interleukin 2 receptor expression was measured on peripheral blood lymphocytes in the London group and was markedly reduced in the cyclosporin patients compared with the placebo group. ${ }^{24}$ Unfortunately no assessment of interleukin 2 receptors was made in the Amsterdam group. However, it may well be that the lower dosage regimen did not suppress lymphocyte activation sufficiently to alter the course of the disease. If this was the case activated lymphocytes would still have been available to enter the central nervous system. The fact that the disease activity continued, albeit at a reduced rate, is not surprising even with the total abolition of interleukin 2 receptor expression peripherally since less than $4 \%$ of the cyclosporin enters the cerebrospinal fluid in our patients (unpublished data) and cerebrospinal fluid lymphocytes continued to express interleukin 2 receptors. ${ }^{24}$ In spite of this there was evidence in the London, but not the Amsterdam, patients that immunoglobulin synthesis was reduced in the central nervous system. This can be explained by the more complete suppression of the pool of systemic activated lymphocytes that is available for recruitment to the central nervous system. If this argument is correct the rate of acquisition of disability, number of relapses and severity of relapses should be lower in the treated patients provided the dosage of cyclosporin is high enough. The effect would be most apparent during the initial stages of therapy and ultimately the group of treated patients would acquire the same amount of central nervous system damage as the control patients since competent immunocytes would remain within the central nervous system. Our data are consistent with this hypothesis. Furthermore, the recently published data from a double blind controlled trial of low dose $(<5.0 \mathrm{mg} / \mathrm{kg} /$ day $)$ cyclosporin compared with azathioprine ${ }^{25}$ which showed no difference between the two groups, and the British Medical Research Council Multicentre study of azathioprine ${ }^{26}$ showing at best a marginal benefit of azathioprine (none if non-parametric statistical analysis is used), is consistent with the idea that cyclosporin does not have a useful effect at low dosage.

While there remains some doubt about the magnitude of the beneficial effects of cyclosporin upon the course of the disease in patients with multiple sclerosis there can be no doubt, at least in the dosage given in this trial, that the side effects are sufficiently severe to preclude its routine use. Most of the adverse events observed are well known. Of particular note was the renal dysfunction which was prolonged in some patients and may not be entirely reversible. Some patients had such severe side effects that they had to be withdrawn from the trial, while others could only continue by taking drugs to combat adverse side effects, for example anticonvulsants or antihypertensive drugs, or reducing the dosage. Nearly all the patients who received the high dose of cyclosporin said they felt better on stopping cyclosporin even though they did not complain of depression or lethargy during treatment. Of interest, however, was the absence of significant infections in the cyclosporin group.

In conclusion, cyclosporin given in relatively high dosage for 2 years probably has a small beneficial effect upon the course of multiple sclerosis but adverse effects are of sufficient severity to prevent its routine use in the disease.

We thank Kate Brennen and the late Mike Smith for their tireless collection of laboratory specimens, Dr EJ Thompson for analysis of the CSF, the Department of Clinical Neurophysiology, National Hospital, Queen Square, for VEP recording, the physicians who referred the patients, and Sandoz Pharmaceuticals for the donation of the CsA and placebo. PR and JM are indebted to the late Sir Peter Medawar for his support and advice in setting up the trial. JCK thanks AJM 
Donker and $\mathrm{J}$ Alferink for the renal investigation of the Dutch patients.

\section{References}

1 Batchelor JR. The immunological and genetic abnormalities of multiple sclerosis. In: Mathews WB, Acheson ED, Batchelor JR, Weller RO, eds. McAlpines Multiple Sclerosis. Edinburgh: Churchill Livingstone, 1985:281-300.

2 Mertin J. Drug treatment of patients with multiple sclerosis. In: Koetsier JC, ed. Handbook of Clinical Neurology, 47 (revised series 3). Amsterdam: N Holland Pub Co 1985:187-212.

3 Mertin J, Rudge P, Kremer M, et al. Double blind controlled trial of immunosuppression in the treatment of multiple sclerosis. Final report. Lancet 1982;ii:351-4.

4 Hauser SI, Dawson DM, Lehrich JR, et al. Intensive immunosuppression in progressive multiple sclerosis. $N$ Engl J Med 1983; 308:173-80.

5 Gonsette R, Demonty P, Demonty L. Intensive immunosuppression with cyclophospyamide in multiple sclerosis. Follow up of 110 patients for 2-6 years. J Neurol 1977;214:173-81.

6 Patzold U, Hecker H, Pocklington P. Azathioprine in treatment of multiple sclerosis. J Neurol Sci 1982;54:377-94.

7 Morris PJ. Cyclosporin. In: Morris PJ, ed. Kidney Transplantation, Principles and Practice. 2nd ed. London: Grune \& Stratton. 1984:261-79.

8 Calne RY. Cyclosporin in cadaveric renal transplantation: 5 year follow up of a multicentre trial. Lancet 1987;ii:506-7.

9 Bolton C, Borel JF, Cuzner ML, Davison AN, Turner AM. Immunosuppression by cyclosporin A of experimental allergic encephalomyelitis in Lewis rats. $J$ Neurol Sci 1982;56:147-53.

10 Bunjes D, Hardt C, Rollinghoff M, et al. Cyclosporin A mediates immunosuppression of the primary cytotoxic T-cell response by impairing the releases of Interleukin 1 and Interleukin 2. Eur J Immunol 1981;11:657-61.

11 Alberti S, Boraschi D, Luini W, Tagliabue A. Effects of in vivo treatments with cyclosporin A on mouse cell mediated immune responses. Int J Immunopharmacol 1981;3:357-64.

12 Rumjanek VM, Smith LA, Morley J. Modulation by cyclosporin A of mononuclear cell distribution during experimental allergic encephalomyelitis. Int J Immunopharmacol 1984;6:99-104.

13 Chisholm PM, Drayson MT, Cox JH, Ford WL. The effects of cyclosporin on lymphocyte activation in a systemic graft-vshost reaction. Eur J Immunol 1985;15:1054-9.

14 Mertin J, Mertin LA. Experimental allergic encephalomyelitis and immunosuppression. Proceedings of the joint meeting of the German Neurological Society and the Neurological Societies of the Benelux countries. Poeck HK, Hacke W, Schneider R, et al, eds. Heidelberg: Springer 1987:38-48.

15 Suckling AJ, Baron AW, Reiber $\mathrm{H}$. Chronic relapsing experimental allergic encephalomyelitis-cyclosporin A treatment of relapsing and remitting disease. J Clin Lab Immunol 1986:21: 173-6.

16 Feurer C, Chow LH, Borel JF. Preventive and therapeutic effects of cyclosporin and valine ${ }^{2}$-dihydro-cyclosporin in chronic relapsing experimental allergic encephalomyelitis in the Lewis rat. Immnunology 1988;63:219-23.

17 Schumacher GA, Beebe G, Kibler RE, et al. Problems of experimental trials of therapy in multiple sclerosis: report by the panel of evaluation of experimental trials of therapy in multiple. Ann NY Acad Sci 1965;122:522-68.

18 Kurtzke JF. Further studies on disability evaluation in multiple sclerosis with scale modification. Neurology 1965;15:654-61.

19 Sheikh K, Smith DS, Meade TW, Brennan PJ, Ide L. Assessment of motor function in disorders of chronic disability. Rheum Rehab 1980;19:83-90.

20 Incapacity status scale (ISS). Acta Neurol Scand 1984;70(suppl 101): $182-7$.

21 Link H, Tibling G. Principles of albumin and IgG analyses in neurological disorders. II Evaluation of IgG synthesis within the central nervous system in multiple sclerosis. Scand J Clin Lab Invest 1977;37:397-401.

22 Halliday AM, McDonald WI, Mushin J. Visual evoked response in diagnosis of multiple sclerosis. Br Med J 1973;4:661-4.

23 Millar JHD, Vas CJ, Noronha MJ, Liversedge LA, Rawson MD. Long term treatment of multiple sclerosis with corticotrophin. Lancet 1967;ii:429-31.

24 Calder VL, Bellamy AS, Owen S, et al. Effects of Cyclosporin A on expression of IL2 and IL2 receptors in normal and multiple sclerosis patients. Clin Exp Immunol 1987;70:570-7.

25 Kappos L, Patzold U, Domatsch S, et al. Cyclosporin versus azathioprine in the long term treatment of multiple sclerosis. Ann Neurol 1988;23:56-63.

26 British and Dutch Multiple Sclerosis Azathioprine Trial Group. Double-masked trial of azathioprine in multiple sclerosis. Lancet 1988;ii: 179-83. 
Representing more than $10 \%$ of the total volume I would rather have a smaller and less expensive book.

In conclusion a volume without an obvious theme but which contains excellent individual contributions. It is certainly not one for which I would pay $£ 45$ and I suspect there are few that will be willing to spend precious funds on a work of this kind.

P JENNER

Concepts in Pediatric Neurosurgery. Vol 9. Edited by American Society for Pediatric Neurosurgery. (Pp 236; \$141.50.) Basel: Karger, 1989.

This volume represents the proceedings of the 11th Annual Meeting of the American Society for Paediatric Neurosurgery that was held in February 1988. Once again, the published articles and contributors are to be congratulated on the speedy appearance of a book that is well presented and carries good illustrations.

As in previous editions, a variety of subjects are covered but there are areas of definite emphasis. The book opens with five papers on hydrocephalus and then proceeds to eight papers on paediatric neurooncology. The current interest in avoiding radiotherapy to the developing brain is given the emphasis that one would expect and there is a good description by Robin Humphreys of Toronto of the strange behavioural state (including mutism) that can complicate an otherwise apparently successful removal of a large tumour from the fourth ventricle.

There is only one paper on a cranio-facial subject, the treatment of "Posterior Plagiocephaly" by the use of specially prepared plastic helmets. This is a condition that is unlikely to attract medical attention in this country and the authors of the article are careful not to include any "before and after" photographs by which their work can be judged.

Bruce Storrs and David McLone give a brief but tempting account of the use of selective posterior rhizotomy in the treatment of spasticity associated with myelomeningocele. Their seven cases all presented with evidence of progressive loss of neurological function and underwent first a standard untethering procedure of the spinal cord. When after a suitable follow-up period (often accompanied by neurological improvement), lower limb spasticity remained a significant problem, all seven underwent a selective posterior rhizotomy. All experienced a significant reduction in their spasticity.

R HAYWARD

\section{Correction}

Randomised double blind controlled trial of cyclosporin in multiple sclerosis. P Rudge, JC Koetsier, J Mertin, JO Mispelblom Beyer, HK Van Walbeek, R Clifford Jones, J Harrison, K Robinson, B Mellein, T Poole, JCJM Stokvis, P Timonen J Neurol Neurosurg Psychiatry 1989;52:559-65.

We regret that an error arose in the setting of table 1 of this paper. The error was not the authors' fault and we apologise to them and reproduce the correct version of the table below.

Table 1 Patient data on entry to trial (mean, standard deviation and range)

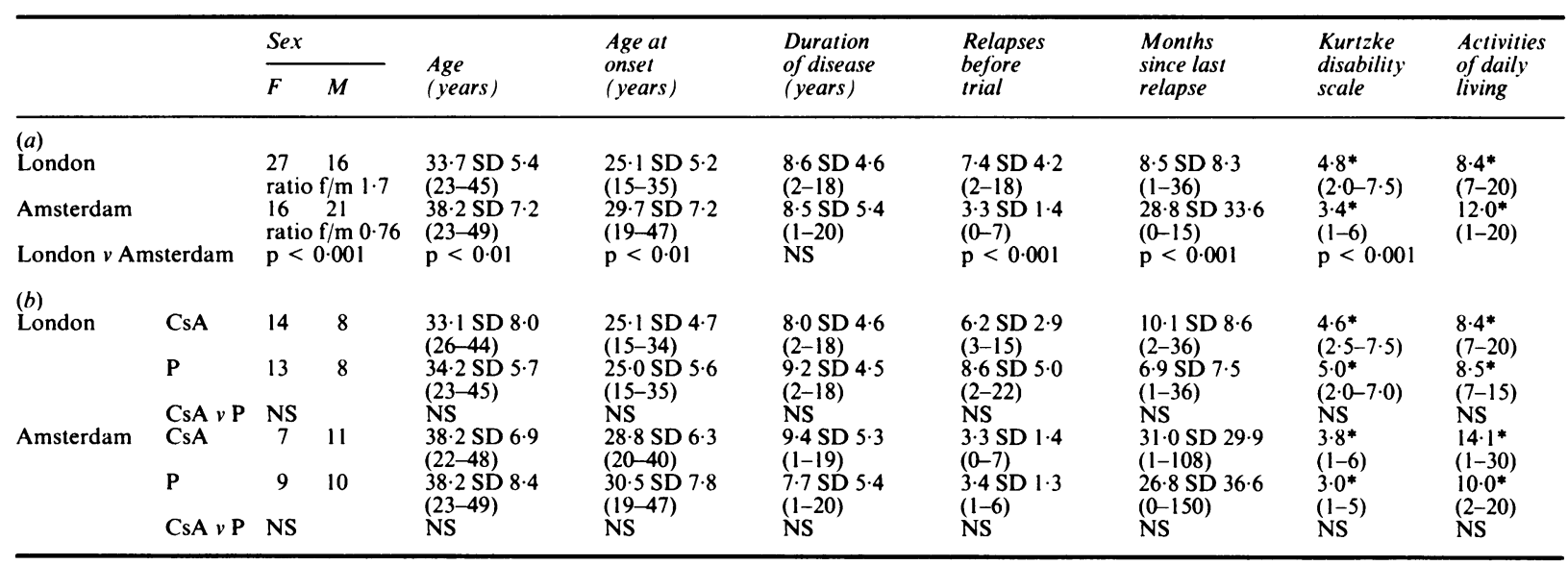

*Data not a normal distribution. CsA, cyclosporin; P, placebo. 